$$
\mathrm{H}(\mathrm{P}, \mathrm{V})=(3 / 2) \mathrm{PV}+\mathrm{PV}=(5 / 2) \mathrm{PV}
$$

Comparison of $\mathrm{H}(\mathrm{P}, \mathrm{V})$ with $\mathrm{U}(\mathrm{P}, \mathrm{V})$, Equation 3 , shows that they share the same basic thermodynamic character since each is a function of the product PV. The difference in multiplying factor is an obvious result of the (added) term PV in the definition of $\mathrm{H}$, Equation 8. Furthermore, this logical difference is consistent with the observed difference between the thermodynamic quantities $C_{V}$ and $C_{P}$. Thus, apart from an incidental difference in multiplying factor, $\mathrm{H}$ is basically identical with $U$ thermodynamically! Here is the paradox: In present thermodynamics, $\mathrm{H}$ is assigned special properties that supposedly make it far superior to $U$ for treating such processes as flow of a fluid or throttling of a gas.

In fact, current uses of enthalpy depend on the following compensation of the error involving the term PdV in Equation 1. The error is introduced when $U$ in Equation 8 is interpreted in terms of ideal gas; consequently, $\mathrm{U}$ is mistakenly pictured as being independent of volume, and, therefore, PdV is taken to be zero. Compensation of this error occurs through the term PV in the definition of $\mathrm{H}$, Equation 8. As shown in Equation 4, the differential of PV includes the term $\mathrm{PdV}$; consequently, this term reappears in $\mathrm{dH}$, even though the thermodynamic treatment in question is based on the "ideal gas" error. Thus, the enthalpy function is paradoxical in that it "works," even though it is based on a $50 \%$ error.

The enthalpy paradox is only the latest of seven major disproofs of the ideal gas concept. In chronological order, the others are:

1. Failure in the 1840 s to use $(P, V)$ as well as (T,V).

2. Evidence in $\mathbf{1 8 5 0}$ from Joule's free-expansion of gases.

3. Boltzmann's admission of his error in the 1870s.

4. Gibbs' equivalent error in the 1870 s resulting in the Gibbs paradox.

5. Poincaré's disproof in 1890 .

6. Proposal by Brillouin and Sommerfeld in the 1920 s on the necessity for negative entropy in biology.

Readers wishing additional information are invited to contact me via telephone or fax at (407) $723-5413$.

\section{Albert G. Guy}

\section{ADDENDUM}

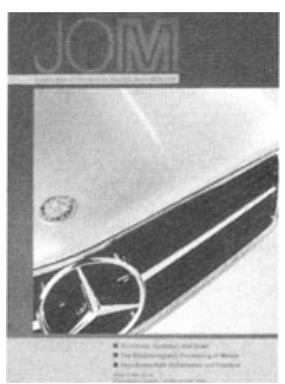

On page 6 of the May 1995 issue, a story in the Materials Design \& Manufacturing Technology section of NEWS \& UPDATE describes the ExoMelt process for melting nickel and iron aluminides. The article credits "researchers at the Oak Ridge National Laboratory" as being the developers of the melting technique. Apparently, this led to a flurry of calls from curious readers wanting more details to the lab's unsuspecting main switchboard. To optimize the communication process, here is the appropriate contact person at the lab: V.K.
Sikka, Metals and Ceramics Division, Oak Ridge National Laboratory, P.O. Box 2008, Oak Ridge, Tennessee 37831-6083; (615) 574-5112; fax (615) 574-4357.

\section{CORRECTION}

On page 29 of the July 1995 issue ("Magnesium Castings for Automotive Applications" by Alan Luo, Jean Renaud, Isao Nakatsugawa, and Jacques Plourde), the first sentence of the sidebar says "a selected list of such applications is give in Table 1." Dumb is

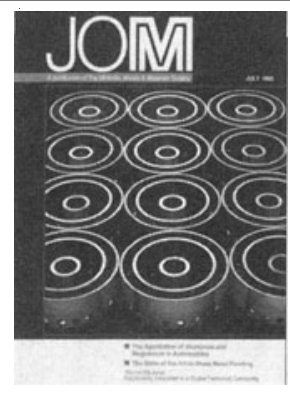

the fact that the "give" should be "given." Dumber is the fact that we neglected to include Table 1 anywhere in the journal. To correct our oversight, the missing table from the sidebarnow appears on this page.

\begin{tabular}{|c|c|}
\hline Company & Parts \\
\hline Chrysler & $\begin{array}{l}\text { Steering column, brackets, valve covers, steering wheels, oil pan, console assemble, } \\
\text { and front headlight retainer }\end{array}$ \\
\hline Ford & $\begin{array}{l}\text { Clutch housing, four-wheel drive transfer cases, steering column, valve covers, } \\
\text { steering wheels, brackets, manual transmission case housing, engine manifold } \\
\text { cover, and bench seat support }\end{array}$ \\
\hline General Motors & $\begin{array}{l}\text { Clutch housing, transmission stators, clutch pistons, inlet manifolds, cam covers, } \\
\text { valve covers, brackets, steering column, oil filter adapters, and instrument panels }\end{array}$ \\
\hline Audi & Instrument panel support \\
\hline BMW & Wheels, gearbox housing, V8 engine block, and brackets \\
\hline Mercedes-Benz & Seat frames, cylinder head covers, and wheels \\
\hline Porsche & $\begin{array}{l}\text { Wheels, intake manifold, crankcase, chain housing, gearbox, gearbox front cover, } \\
\text { and oil pump housing }\end{array}$ \\
\hline Honda & Cylinder head cover, wheels, and valve covers \\
\hline Toyota & Steering wheels, valve covers, and brackets \\
\hline
\end{tabular}

\title{
UPCOMING EDITORIAL TOPICS
}

Month Process-Oriented Topics Materials-Oriented Topics Manuscripts Due

$\begin{array}{ll}\text { October } 1995 & \text { Process Modeling: } \\ & \text { From Lab to Shop }\end{array}$

PLUS: Recycling Metals and Engineered Materials

November 1995 Developments in the Primary Aluminum Industry

December 1995 Value-Addition Metallurgy: Aspects, Examples, and Development PLUS: Materials for Hypersonic Flight Systems

January 1996 Developments in Zinc Process Technology

$\begin{array}{cl}\text { February } 1996 & \begin{array}{l}\text { Superplasticity and } \\ \text { Superplastic Forming }\end{array} \\ \text { PLUS: Quarterly Coverage of Aluminum Processing }\end{array}$

March 1996

The Technology and Economics of Materials Waste Reduction, Recycling, Recovery, and Remediation

April $1996 \quad 1996$ Review of Extraction and Processing

\section{May 1996 The Coating of Materials for Corrosion Resistance} PLUS: Quarterly Coverage of Aluminum Processing

Processing, Microstructure, and Properties of Ceramics and Ceramic-Matrix Composites

Deadline Past

The Search for Ultra-Hard

Deadline Past Materials: C-N Compounds

\section{Epitaxial Crystal Growth \\ Deadline Past Deadline Past}

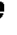

